\title{
Risk Factors and Short Term Morbidities Associated With Term-Small for Gestational Age Babies Delivered at Nepalgunj Medical College
}

\author{
Kanodia $\mathrm{P}^{1}$, Verma $\mathrm{AK}^{1}$, Adhikari $\mathrm{S}^{1}$
}

\begin{abstract}
Introduction: Small for gestational age (SGA) refers to birth weight of neonates less than $10^{\text {th }}$ percentile for gestational age or $2^{\text {nd }}$ standard deviation below the population norms on the growth charts. Aims: To identify common risk factors and common morbidities for small for gestational age babies. Methods: This is a cross sectional descriptive study and it has been conducted at Department of pediatrics, Nepalgunj Medical college which is a tertiary level teaching hospital located in western part of Nepal. All term small for gestational age neonates born during study period from January 2020 to December 2020 were included. Detailed baseline demographic and clinical profile has been collected and recorded in the predesigned Proforma. Results: The most common risk factors associated with small for gestational age babies in our study were maternal hypertension (14.6\%), maternal GDM(9.6\%), Urinary Tract Infection (UTI) in $1^{\text {st }}$ or $2^{\text {nd }}$ trimester of pregnancy, maternal anemia, smoking, alcohol consumption, hypothyroidism and congenital heart disease. The most common short term complications associated with Small for gestational age babies were hypoglycemia and Meconium aspiration syndrome. Conclusion: The most common risk factors associated with Small for gestational age babies in our study were maternal hypertension, maternal Gestational Diabetes Mellitus (GDM), Urinary Tract Infection in $1^{\text {st }}$ or $2^{\text {nd }}$ trimester of pregnancy, maternal anemia, smoking, alcohol consumption, hypothyroidism and congenital heart disease. The most common short term complications associated with Small for gestational age babies were hypoglycemia and Meconium aspiration syndrome (MAS).
\end{abstract}

Keywords: Hypoglycemia, Meconium aspiration syndrome , Small for gestational age

Authors:

\author{
1. Dr. Piush Kanodia \\ 2. Dr. Arun Kumar Verma \\ 3. Dr. Sumit Adhikari \\ ${ }^{1}$ Department of Pediatrics, Nepalgunj Medical College and Teaching Hospital, Nepalgunj, Banke
}

\section{Address for Correspondence:}

Dr. Piush Kanodia

Associate Professor

Department of Pediatrics

Nepalgunj Medical College and Teaching Hospital

Nepalgunj, Banke

Email: piushkanodia@yahoo.com

\section{INTRODUCTION}

Small for gestational age (SGA) refers to birth weight of neonates less than 10th percentile for gestational age or two SD below the population norms on the growth charts. ${ }^{1-4}$

In a study by Katz et al the prevalence of SGA ranged from $10.5 \%$ to $72.5 \%$. Similarly prevalence of small-for-gestationalage (SGA) ranged from $12.0 \%$ to $78.4 \%$ in India. ${ }^{5}$ Most smallfor-gestational-age infants were born in India, Pakistan, Nigeria, and Bangladesh. ${ }^{6}$ SGA can occur due to various known risk factors including the maternal, placental and fetal. Common maternal risk factors include maternal age TORCH infections, congenital HIV infection, and syphilis. Common placental risk factors include placental weight less than 350 gram, placental dysfunction secondary to pregnancy induced hypertension, pre-eclampsia. $^{7-14}$ SGA neonates can develop various complications/ co-morbidities. Short term complications include perinatal asphyxia, meconium aspiration, persistent pulmonary hypertension, hypothermia, hypoglycemia, hyperglycemia, hypocalcaemia, polycythemia, jaundice; feeding difficulties and feed intolerance, necrotizing enterocolitis, late-onset sepsis and pulmonary hemorrhage. Longterm complications as stated by Barkers were type II diabetes, obesity, hypertension, coronary heart disease, dyslipidemia, insulin resistance syndrome, growth retardation (wasting and stunting), neurodevelopmental delay. ${ }^{15,16-19}$ Our study is important as there is paucity of data in our part of Nepal for establishing direct and causal relationship of SGA babies with known common risk factors and their short term complications. Hence the study was conducted to identify common risk factors and common morbidities for SGA babies.

\section{METHODS}

This is a cross sectional descriptive study and it has been conducted at Department of pediatrics, NGMC which is a tertiary level teaching hospital located in western part of 
Nepal. All Term SGA neonates born during study period from January 2020 to December 2020 were included. Baby with gross congenital anomalies, out born babies, parent's refusal and Newborn to mothers with unreliable gestational age excluded from study.

All newborns meeting the inclusion criteria were enrolled in the study and a written consent has been taken in local language. Detailed baseline demographic and clinical profile has been collected and recorded in the predesigned Proforma. The investigation was done as per NICU protocol and was noted. The complications that develop during hospital stay were noted. Outcomes like discharge or death were noted and all were entered in predesigned Proforma. All data were recorded and analyzed in Statistical package for Social science (SPSS) version 20.0 entered in Microsoft excel 2010.

\section{RESULTS}

There were total of 323 SGA neonates who met inclusion criteria and were enrolled in the study. Among the 323 neonates, most of the SGA babies were between 2000-2500 grams $(73.1 \%), 18.6 \%$ babies were $>2500$ grams but SGA and $8.4 \%$ of babies were below 2000 grams. Male and female ratio was found to be almost equal. Among 323 SGA neonates, $84.5 \%$ of mothers were between $20-30$ years. Most of them were primigravida (56\%) and most of them belonged to Upper caste ethnicity(51.3\%). 39\% of population belonged to lower middle class followed by upper lower class(22.9\%) socioeconomic status. $34.9 \%$ of mother had education up to school level followed by diploma (31.2\%). Most of them were homemaker (68.1\%).

One fourth babies had no identifiable risk factors. Among the identifiable risk factors gestational hypertension, oligohydramnios, gestational diabetes mellitus, UTI were found to be common. This is depicted in table I.

\begin{tabular}{lcc}
\multicolumn{1}{c}{ Risk factors } & No. of SGA baby & Percentage \\
\hline Gestational HTN & ( $\mathbf{n = 3 2 3 )}$ & (\%) \\
\hline Oligohydramnios & 47 & 14.6 \\
\hline Gestational DM & 47 & 14.6 \\
\hline UTI (1 st and 2nd trimester) & 31 & 9.6 \\
\hline Anemia & 31 & 9.6 \\
\hline Smoking during pregnancy & 20 & 6.2 \\
\hline Alcohol abuse & 18 & 5.6 \\
\hline Hypothyroidism & 14 & 4.3 \\
\hline $\begin{array}{l}\text { Congenital Heart disease in } \\
\text { mother }\end{array}$ & 10 & 3.1 \\
\hline $\begin{array}{l}\text { Multiple pregnancy, HIV infection, } \\
\text { h/o fever in 1st trimester }\end{array}$ & 9 & 2.8 \\
\hline No risk factors & 11 & 3.35 \\
\hline
\end{tabular}

Table I: Association between maternal Risk factors SGA baby

Common morbidities associated with SGA babies: APGAR at 5 min: Among 323 neonates, 96\% had normal APGAR score at $5 \mathrm{~min}$ and 4\% had APGAR score in between 4-7 who were diagnosed as perinatal depression. More than $2 / 3 \mathrm{rd}$ had no immediate morbidities. The common short term morbidity was hypoglycemia (13.3\%), MAS (9.9\%), neonatal hyperbilirubinemia (6.8\%) and Sepsis 15(4.6\%). This is depicted in table II.

\begin{tabular}{lcc}
\multicolumn{1}{c}{ Variable SGA neonate } & ( $\mathbf{n =}$ & Percentage \\
Hypoglycemia & $\mathbf{3 2 3}$ & (\%) \\
MAS & 43 & 13.3 \\
NNH & 32 & 9.9 \\
Sepsis & 22 & 6.8 \\
Feeding difficulties & 15 & 4.6 \\
\hline Perinatal asphyxia & 10 & 3.1 \\
\hline Hypothermia & 8 & 2.5 \\
Polycythemia & 7 & 2.2 \\
No complication & 1 & 0.3 \\
\hline Other complication & 216 & 66.8 \\
\hline
\end{tabular}

Table II: Associated co-morbidities

Other complications include Seizure, thrombocytopenia, congenital heart disease (ASD, VSD, PDA), TTNB, septic ileus, AKI, anemia.

\section{Short term morbidities and outcome associated with term SGA babies:}

Among 323 term SGA babies 33\% had complications, of which $15.7 \%$ had 1 complication and $17.3 \%$ had multiple complications. All cases were discharged without any neurological impairment. Duration of stay were $\leq 3$ days in $41.1 \%$ and more than 3 days in $51.1 \%$.Duration of stay were 3 days in 51.1.There were no deaths in the studied subjects and most of the babies were discharged within 3 days of admission.

\section{DISCUSSION}

We found 9.6\% (31) of mother with SGA babies having GDM. GDM is usually associated with LGA babies. If the GDM mother develops vasculopathy it can lead to SGA. However study done in Nepal found that gestational Diabetes Mellitus caused IUGR in $12(6.06 \%)$ cases. ${ }^{20}$ One (9.6\%) mother with SGA babies had UTI during $1^{\text {st }}$ or $2^{\text {nd }}$ trimester. Manandhar $\mathrm{T}$ and et al at College of Medical Sciences, Chitwan, in 2018 found that IUGR developed in 6(24\%) cases with maternal UTI. ${ }^{21}$ Only 20 (6.2\%) mothers with SGA babies had anemia. Similarly Paudel $\mathrm{G}$ et al, found that prevalence of maternal anemia among SGA were $6.5 \%$ with AOR 1.29 (0.78 to 2.11), $P=0.321 . .^{22}$

Low hemoglobin levels may impair oxygen delivery to the body, creating an environment of oxidative stress or chronic hypoxia, which could then cause fetal growth restriction. 18 (5.6\%) mother who were chronic smoker had SGA babies. As per Sun $S$ and et al in U.S smoking during pregnancy causes $19.1 \%$ term SGA babies in compared to $9.1 \%$ in non-smokers. ${ }^{23}$ Nicotine 
induces the release of maternal catecholamines that reduce placental perfusion subsequently leading to SGA.

Also $14(4.3 \%)$ had habit of regular alcohol intake of small to moderate amount, Maternal alcohol consumption during pregnancy has been associated with the disruption of metabolic pathways in the mother, thus impairing fetal development. ${ }^{23}$ In the present study, other maternal risk factors contributing to SGA babies were observed and according to Shrestha et al hypothyroidism contributing to IUGR were $5 \% .{ }^{20}$ Mandhar et al found the other maternal risk factor causing IUGR were chronic renal disease, rheumatic disease, uterine anomaly, obstetric cholestasis, antiphospholipid antibodies(APLA) and chemotherapy. ${ }^{21}$

The $107(33.12 \%)$ babies suffered from some forms of neonatal complications. 1-2 complications were observed in 93 (28.79\%) babies and $>2$ complications in 14(4.3\%). Most common short term complications were found to be hypoglycemia 43(13.3\%). Lubencho et $\mathrm{al}^{24} \mathrm{Hosagasi}$ et $\mathrm{al}^{24}$ and Jing Liu et $\mathrm{al}^{26}$ found the probable cause of hypoglycemia in these SGA babies is due to metabolic disturbances related to glucose and fatty acid metabolism. Meconium aspiration syndrome 32(9.9\%) was other important comorbidity following hypoglycemia. Etiology of the passing of meconium is unclear, but some theories exist on the passage of meconium is a response to fetal hypoxia. ${ }^{21}$ Other complications were jaundice $22(6 . \%)$ cases, sepsis $15(4.6 \%)$ cases, feeding difficulties $10(3.1 \%)$ cases, perinatal asphyxia $8(2.5 \%)$ and hypothermia $7(2.2 \%)$ cases. $10(3 \%)$ had either Polycythemia, Seizure, thrombocytopenia, congenitalstay. ${ }^{27}$ The probable reason for polycythemia, birth asphyxia, early meconium passage in SGA babies could be due to long-term intrauterine hypoxia due to placental dysfunction. There were no deaths in the studied subjects and most of the babies were discharged within three days of admission.

\section{LIMITATION}

Multicentre study is needed for betterment SGA baby's outcome and follow up should be done late term complications.

\section{CONCLUSION}

In summary the most common risk factors associated with SGA babies in our study were maternal hypertension, maternal GDM, UTI in 1st or 2nd trimester of pregnancy, maternal anemia, smoking, alcohol consumption, hypothyroidism and congenital heart disease. The most common short term complications associated with SGA babies were hypoglycemia and MAS.

\section{REFERENCES}

1. Eveleth PB. Physical Status: The Use and Interpretation of Anthropometry. Report of a WHO Expert Committee. Am J Hum Biol [Internet]. 1996;8(6):786-7. Available from: http://www.ncbi.nlm.nih.gov/pubmed/ 8594834

2. Chernausek SD. Update: Consequences of Abnormal Fetal Growth. J ClinEndocrinolMetab [Internet]. 20121;97(3):68995. Available from: https://academic.oup.com/icem/

\section{article/97/3/689/2536264}

3. Black RE. Global Prevalence of Small for Gestational Age Births. In: Nestle Nutrition Institute Workshop Series [Internet]. 2015. p. 1-7. Available from: https://www.karger. com/Article/FullText/365790

4. Sharma D, Shastri S, Sharma P. Intrauterine Growth Restriction: Antenatal and Postnatal Aspects. Clin Med Insights [Internet]. 2016;10:67-83. Available from: https://www.mendeley.com/catalogue/626f3570-88f535baa7b8-49e8196243e5/?utm_source=desktop\&utm_ medium=1.19.4\&utm_ campaign=open_catalog\&userDocu mentld=\%7B6733e969-3dc1-48be9fda-403f280a4bbf\%7D

5. Katz J, Wu LA, Mullany LC, Coles CL, Lee ACC, Kozuki N, et al. Prevalence of small-for-gestational-age and its mortality risk varies by choice of birth-weight-for-gestation reference population. Wright L, editor. PLoS One [Internet]. 2014;9(3):e92074. Available from: http://www.ncbi.nlm. nih.gov/pubmed/24642757

6. Lee ACC, Katz J, Blencowe H, Cousens S, Kozuki N, Vogel JP, et al. National and regional estimates of term and preterm babies born small for gestational age in 138 low-income and middle-income countries in 2010. Lancet Glob Heal [Internet]. 2013;1(1):e26-36. Available from: http://www. ncbi.nlm.nih.gov/pubmed/25103583

7. Nam H-K, Lee K-H. Small for gestational age and obesity: epidemiology and general risks. Ann PediatrEndocrinolMetab [Internet]. 2018;23(1):9-13. Available from: http://e-apem. org/journal/view.php?doi= 10.6065/apem.2018.23.1.9

8. Graner S, Klingberg-Allvin M, Phuc HD, Huong DL, Krantz G, Mogren I. Adverse perinatal and neonatal outcomes and their determinants in rural Vietnam 1999-2005. Paediatr Perinat Epidemiol [Internet]. 2010;24(6):535-45. Available from: http://doi.wiley.com/10.1111/i.1365-3016.2010.01135.x

9. Ota E, Ganchimeg T, Morisaki N, Vogel JP, Pileggi C, OrtizPanozo $\mathrm{E}$, et al. Risk factors and adverse perinatal outcomes among term and preterm infants born small-for-gestationalage: Secondary analyses of the WHO multi-country survey on maternal and newborn health. PLoS One. 2014;9(8).

10. Paudel PG, Sunny AK, Gurung R, Gurung A, Malla $\mathrm{H}$, Budhathoki SS, et al. Prevalence, risk factors and consequences of newborns born small for gestational age: $\mathrm{A}$ multisite study in Nepal. BMJ Paediatr Open. 2020;4(1):1-9

11. Chen $\mathrm{S}$, Zhu R, Zhu H, Yang H, Gong F, Wang L, et al. The prevalence and risk factors of preterm small-forgestational-age infants: a populationbased retrospective cohort study in rural Chinese population. BMC Pregnancy Childbirth [Internet]. 2017;17(1):237. Available from: http://bmcpregnancychildbirth.biomedcentral.com/ articles/10.1186/s12884-017-1412-7

12. Christian P, Lee SE, Donahue Angel M, Adair LS, Arifeen SE, Ashorn $\mathrm{P}$, et al. Risk of childhood undernutrition related to small-for-gestational age and preterm birth in lowand middle-income countries. Int J Epidemiol [Internet]. 2013;42(5):1340-55. Available from: https://academic.oup. com/ije/article-lookup/doi/10.1093/ije/dyt109 
13. .Dashe JS, McIntire DD, Lucas MJ, Leveno KJ. Effects of symmetric and asymmetric fetal growth on pregnancy outcomes. ObstetGynecol [Internet]. 2000;96(3):3217. Available from: http://www.ncbi.n/m.nih.gov/ pubmed/10960619

14. McCowan L, Horgan RP. Risk factors for small for gestational age infants. Best Pract Res ClinObstetGynaecol [Internet]. 2009;23(6):779-93. Available from: http://www.ncbi.nlm. nih.gov/pubmed/19604726

15. .Liu J, Wang X-F, Wang Y, Wang H-W, Liu Y. The Incidence Rate, HighRisk Factors, and Short- and Long-Term Adverse Outcomes of Fetal Growth Restriction. Medicine (Baltimore) [Internet]. 2014;93(27):e210. Available from: http:// journals.Iww.com/00005792-201412020-00032

16. R K. Profile of Neonatal Jaundice in Low Birth Weight InfantsComparison Between AGA and SGA Subgroups. 2013;20103.

17. Halliday HL. Neonatal management and longterm sequelae. Best Pract Res ClinObstetGynaecol [Internet].2009;23(6):871-80. Available from: http://dx.doi. org/10.1016/i.bpobgyn.2009.06

18. Nardozza LMM, Araujo Júnior E, Barbosa MM, Caetano $A C R$, Lee DJR, Moron AF. Fetal growth restriction: current knowledge to the general Obs/Gyn. Arch GynecolObstet [Internet]. 2012;286(1):1-13. Available from: http://www. ncbi.nlm.nih.gov/pubmed/22526452

19. Clayton PE, Cianfarani S, Czernichow P, Johannsson G, Rapaport R,Rogol A. Management of the child born small for gestational age through to adulthood: a consensus statement of the International Societies of Pediatric Endocrinology and the Growth Hormone Research Society. J ClinEndocrinolM etab[Internet].2007Mar;92(3):80410.Availablefrom:http:// www.ncbi.nlm.nih.gov/pubmed/17200164

20. Shrestha A. Analysis of frequency and risk factors for intrauterine growth restriction. Int J Sci Reports. Available from: $\quad$ http://www.sci-rep.com/index.php/scirep/article/ view/358

21. Barone G, Maggio L, Saracino A, Perri A, Romagnoli C, Zecca E. How to feed small for gestational age newborns. Available from: http://www.ncbi.nlm.nih.gov/pubmed/ 23663313

22. Paudel PG, Sunny AK, Gurung R, Gurung A, Malla $\mathrm{H}$, Budhathoki SS, et al. Prevalence, risk factors and consequences of newborns born small for gestational age: $\mathrm{A}$ multisite study in Nepal. BMJ Paediatr Open. 2020;4(1):1-9.

23. Sun S, Spangler KR, Weinberger KR, Yanosky JD, Braun JM, Wellenius GA. Ambient Temperature and Markers of Fetal Growth: A Retrospective Observational Study of 29 Million U.S. Singleton Births. Environ Health Perspect [Internet]. 2019;127(6):67005. Available from: http://www.ncbi. nlm. nih.gov/pubmed/31162981

24. Lubchenco LO, Bard $\mathrm{H}$. Incidence of hypoglycemia in newborn infants classified by birth weight and gestational age. Pediatrics [Internet]. 1971 May;47(5):831-8. Available from: http://www.ncbi.nlm.nih.gov/pubmed/ 5573868
25. Hosagasi NH, Aydin M, Zenciroglu A, Ustun N, Beken S. Incidence of hypoglycemia in newborns at risk and an audit of the 2011 American academy of pediatrics guideline for hypoglycemia. PediatrNeonatol [Internet]. 2018;59(4):36874. Available from: http://www.ncbi.nlm.nih.gov/ pubmed/29198616

26. Liu J, Wang X-F, Wang Y, Wang H-W, Liu Y. The Incidence Rate, HighRisk Factors, and Short- and Long-Term Adverse Outcomes of Fetal Growth Restriction. Medicine (Baltimore) [Internet]. 2014 Dec; 93(27):e210. Available from: http:// journals.Iww.com/00005792-201412020-00032

27. Ghaffar A, Suleman, Ali P. Risk factors and acute complications of small for gestational age term newborns. Pakistan J Med Heal Sci [Internet]. 2015;9(1):299-300. Available from: https://www.researchgate.net/ publication/282299487 Risk_factors_and_acute_complications_of_small_for_ gestational_age_term_newborns 